\title{
Editorial
}

\section{Revista de Psiquiatria Clínica indexada no ISI}

\author{
WAGNER F. GATTAZ
}

Editor-Chefe

A REVISTA DE PSIQUIATRIA CLÍNICA foi indexada no ISI Web of Knowledge. Com início retroativo ao volume 31 (1) de 2008, a RPC passou a ser coberta pelo Science Citation Index Expanded (também conhecido como SciSearch ${ }^{\circledR}$ ) e pelos Journal Citation Reports/Science Edition, que publicarão todos os seus títulos e os seus Abstracts. Esta indexação pelo Institute for Scientific Information, somada às outras que já temos (SciELO, SCOPUS etc.), dará um importante impulso à divulgação das RPC junto à comunidade científica internacional.

O ISI é uma das maiores e mais importantes fontes de indexação científica. Existe uma grande competitividade entre os periódicos científicos para obter essa indexação. Critérios rígidos são adotados, como elevada qualidade científica, nível internacional do corpo e da comissão editoriais, constância e pontualidade das publicações. A nossa indexação é, portanto, uma vitória conjunta de toda a equipe de Editores, Editores de Áreas e da nossa Comissão Editorial, que vem dedicando de forma generosa parte de seu escasso tempo para a RPC. Mas, sobretudo, essa conquista se deve aos nossos Autores que nos têm enviado para publicação trabalhos de excelência. Todo esse trabalho não teria se concretizado sem a eficiência da SEGMENTO FARMA, liderada aqui pelos nossos parceiros Idelcio Patricio, Daniela e equipe, que vem garantindo a qualidade gráfica e a pontualidade de publicação da RPC. Por trás dos bastidores, nossa assistente editorial Sandra Picchiotti cuida com presteza de, simplesmente, "todo o resto". Assim, em nome da RPC, agradeço a todos que participaram e colaboraram ativamente nesse processo.

Pelas atuais normas da CAPES, com essa indexação a classificação da RPC passará de QUALIS Nacional A para QUALIS Internacional C. Este é o primeiro passo para que as citações das publicações na RPC passem a ser computadas visando, após um ano, ao cálculo de um Fator de Impacto. Havendo um fator de impacto < 1, passaremos para QUALIS B, e quando for > 1, seremos QUALIS A. Essa classificação serve para avaliar as publicações dos programas de pós-graduação, assim como critério para alguns programas para conclusão de pós-graduação (por exemplo, a necessidade mínima de publicações em QUALIS Internacional B e A para mestrado e doutorado, respectivamente).

Portanto, a indexação da RPC torna-a mais atraente para os autores, resultando numa maior competição por espaço para publicar manuscritos excelentes. A conseqüência inevitável será um aprimoramento ainda maior da qualidade científica da RPC. Com isso, poderemos cumprir melhor a nossa missão: ser um dos principais órgãos de informação científica e educação continuada para os psiquiatras de língua portuguesa.

Como ocorre na vida, ao vencermos uma etapa colocamos logo em nossa mira um outro desafio mais ambicioso. O nosso próximo desafio será continuarmos nosso trabalho para obtermos a indexação da RPC pelo MEDLINE. Contando com o mesmo empenho dessa equipe, estou cer to de que em breve venceremos mais essa etapa para servirmos cada vez melhor os nossos leitores.

Com tudo isso, fica claro também que teremos mais trabalho pela frente, visto que contamos com um aumento no número de manuscritos submetidos. Para reforçar as nossas fileiras, convidamos o Professor Geraldo Busatto para integrar o corpo de editores da RPC. O Prof. Busatto vinha exercendo com maestria a função de Editor de Área para Artigos Originais. Sua passagem para Editor nos dará suporte para orientarmos os rumos científicos e administrativos da RPC.

Veja a RPC no site do ISI, no qual os números de 2008, incluindo um suplemento, já se encontram indexados (entrar "Revista de Psiquiatria Clínica" no campo "Publication Name" de http://apps.isiknowledge.com/ WOS_GeneralSearch_input.do?product=WOS\&SID=U2DL55p8ikhMj3Enmhc\&search_mode=GeneralSearch). 